\title{
EL CATALOGO PROVINCIAL DE ESPACIOS NATURALES PROTEGIBLES Y SU PROBLEMATICA
}

719:502.7

\author{
por
}

\author{
Ignacio Docavo Alberti \\ Vicepresidente de la Diputación Provincial de Valencia. \\ Catedrático-Director del Departamento de Zoología y Biología \\ de la Facultad de Ciencias
}

SUMARIO: I. LA DESTRUCCION DE LA NATURALEZA AMENAZA NUESTRAS VIDAS.-II. EL CATALOGO, MEDIDA CAUTELAR URGENTE PARA SALVAR LA PROVINCIA. - III. LA DIPUTACION PROVINCIAL EN LA PROMOCION DE PARQUES NATURALES.IV. LA ZONIFICACION DEL PARQUE NATURAL Y LOS USOS PER. MITIDOS.-V. LA ORDENACION DE LA SIERRA CALDERONA: LA COTA TRESCIENTOS. - VI. EL MONTE PUBLICO, LOS ENCLAVES PRIVADOS Y LAS URBANIZACIONES.-VII. ESPACIOS NATURALES PROVINCIALES E INTERPROVINCIALES A PROTEGER: 1. Espacios naturales interesantes de la Provincia de CaStellón de la Plana. 2. Espacios naturales interesantes de la Pro. vincia de ALICANTE.-VIII. URGENCIA DE AYUDAS ECONOMICAS PARA LA PROMOCION DE NUESTROS ESPACIOS NATURALES.

\section{LA DESTRUCCION DE LA NATURALEZA AMENAZA NUESTRAS VIDAS}

El hombre de la calle es bombardeado desde la prensa, la radio y la televisión por una serie de vocablos que están a la orden del día y que constituyen la máxima actualidad: polución, contaminación, defensa de los animales, las plantas y el paisaje y, en una palabra, la necesidad urgente e ineludible de defender la Natura- 
leza y nuestro medio ambiente, para lo cual muchos países se han declarado en estado de verdadera emergencia y los más altos organismos internacionales comienzan a preocuparse.

En efecto, la llamada era industrial que vivimos. dota al hombre de medios de acción extremadamente potentes.

Vamos a analizar las causas de un cierto número de estas acciones equívocas, pues la lista completa sería demasiado larga para establecer y de todos modos se acrecienta cada día un poco más.

Entre las más graves están las que han provocado la desaparición total de grupos de animales o vegetales. Se ha podido hablar de "gran masacre» sobre este tema, puesto que en un cierto número de casos es la voluntad deliberada y un cierto deseo gratuito de destruir los que han guiado al hombre. Es así que un cierto número de mamíferos y de aves han desaparecido de la superficie de la tierra, y se piensa que una especie de ave desaparece todavía definitivamente cada año. En unos siglos cerca de 300 formas han desaparecido, y debemos observar deprisa lo que está todavía vivo y que nuestros hijos no descubrirán más que en los museos o en los libros de dibujos.

Un segundo medio muy amenazado está constituido por los habitats húmedos, marismas y pantanos. Desde siempre estas zonas han sido consideradas como insalubres y cargadas de todos los males. Por otra parte, la política de recuperación de las tierras cultivables ha provocado la transformación por drenaje de superficies muy importantes. Ahora bien, ello es todavía la persistencia de un error ecológico, puesto que estos medios son de una alta productividad biológica. Las investigaciones del profesor ODum en los Estados Unidos han demostrado una producción de 20 toneladas de materia orgánica seca por año y por hectárea, mientras que un campo de trigo no produce más de 3,5. Esta materia orgánica, por supuesto, no se puede utilizar directamente, pero entra en un ecosistema y asegura el alimento de peces y aves. Estas regiones protegidas constituyen verdaderos museos al aire libre, como la Camarga, la Albufera o las marismas del Guadalquivir.

Por fin, la forma más actual y la más moderna de agresión contra la Naturaleza es el verdadero aluvión de desperdicios, sustancias químicas o materiales físicos que alteran sus propiedades; ésta constituye la polución en el sentido amplio. Casi todos los medios están envenenados en diversos grados. Hemos evocado ya estos desperdicios de las ciudades vertidos en los ríos, más allá de su 
capacidad de depuración natural. Estos venenos son muchas veces productos químicos producidos por las industrias. Los venenos orgánicos son principalmente los detergentes domésticos e industriales y los pesticidas utilizados en agricultura. Estas sustancias no son destruidas en las aguas por falta de agentes bacteriológicos es. pecíficos y persisten mucho tiempo.

Las aguas dulces no son las únicas en ser amenazadas, y los océanos, a pesar de su extensión, comienzan a mostrar signos de acabamiento. Cuántas veces se nos ha dicho que los océanos son inagotables y que su masa misma los protege. Pero ellos reciben todos los desechos de la vida de la superficie de la tierra que tienen por papel destruirlos. Pero lentamente aparece el espectro de la polución global. Los venenos más conocidos son los productos petrolíferos que provienen sea del lavado de las bodegas en alta mar —esto está prohibido actualmente-, sea de naufragios de barcos de transportes. Con el desarrollo de las técnicas de perforación en el mar este peligro se hace cada día más importante y con fatales consecuencias para la fauna. Pero otras poluciones comienzan a aparecer: las sales de mercurio, que han contaminado los cargamentos de atún en el Pacífico, los desechos radiactivos y también los gases neurotóxicos que se entierran en los fondos marinos, y bien inconscientemente, sin saber si las corrientes marinas no los harán resurgir un buen día.

Los venenos no sólo circulan por el suelo y por las aguas. La polución atmosférica es también preocupante. Estas poluciones están constituidas bien por nubes de polvo debido a la proximidad de las fábricas, principalmente de las de cemento, ya por productos químicos. Estos productos son principalmente el anhidrido sulfuroso: dos millones de toneladas por año en Francia; el trióxido de azufre, que da en el aire ácido sulfúrico muy corrosivo, y los óxidos de nitrógeno, que son uno de los elementos más tóxicos de los smog, esas nieblas perniciosas de las grandes ciudades. Se encuentran también productos resultantes de la combustión de la gasolina, dotados de propiedades cancerígenas; del flúor, que provoca las lesiones de los huesos; del cloro proviniente de la destrucción de materias plásticas. El aire irresistible de las ciudades no es una leyenda, y las perspectivas de extensión de éstas, a las que se ha llamado "megalópolis», tienen de qué hacer temblar.

Otro gravísimo problema es el de la eliminación de las basuras y otros residuos urbanos que, frente a los industriales, podríamos 
llamar "domésticos», lo que, de no llegarse a una rápida solución, va a convertir no sólo los alrededores de nuestras ciudades y pueblos, sino también los campos y montes, en un gigantesco basurero.

Pavoroso es el problema también de la degradación y destrucción del monte, no sólo por las talas de que fue objeto para ganar tierras a la agricultura, lo que hoy se está limitando grandemente en las Naciones de Europa y América, sino por los terribles fuegos en los montes. La Europa mediterránea está siendo desforestada en gran parte debido a los voraces e implacables incendios. Los bosques mediterráneos de pinos, llenos de grandes matorrales, son una yesca natural puesta a prender en cualquier instante para sembrar la ruina y la desolación. La Región Valenciana es una de las más castigadas por el fuego.

\section{EL CATALOGO, MEDIDA CAUTELAR URGENTE PARA SALVAR LA PROVINCIA}

Valencia se está industrializando a marchas forzadas. La urbe y el área metropolitana aumentan sin parar en su demografía.

Los más bellos parajes naturales de nuestra Provincia y Región están amenazados más o menos inmediatamente.

Nuestra costa ha sido deshecha y convertida en un muro de cemento.

La Albufera, gravemente enferma, agoniza ante nuestra impotencia, pues los remedios terapéuticos que con muy buena voluntad y esfuerzo hemos podido utilizar, hasta ahora no han conseguido sino mejorar de momento a un lago en trance de muerte biológica.

La Dehesa, maravilla de las asociaciones vegetales de dunas y marismas, tesoro científico de inapreciable valor, paisaje maravilloso y tradicional valenciano, ha sido degradado en la mayoría de su superficie por el nefasto serpentear de amplias pistas o carreteras, que conducen a esas enormes moles de cemento que se elevan como gigantes vencedores de la Naturaleza hacia el cielo valenciano.

Nuestros montes, en gran parte privatizados, van siendo destruidos por incendios, urbanizaciones turísticas, caminos y carreteras, muchas veces mal concebidas y peor planificadas, que matan la vegetación y el paisaje y hacen huir o desaparecer para siempre a la fauna salvaje que los alegraba y daba vida. Ya en las sierras va- 
lencianas, de continuar por este camino, no se oirá el canto de los pájaros, ni el deslizarse el arroyo de aguas puras y cristalinas, ni el murmullo del viento entre las hojas de la arboleda del bosque. El pueblo valenciano no podrá tomar ya en ellos el alimento que para su cuerpo y espíritu proporcionan estos espacios naturales capaces de reponer nuestros nervios rotos en la ciudad y serenar el alma con la vista de maravillosos paisajes. Allí reinará el cemento del chalé y los hormigueantes apartamentos; el canto de los pájaros será sustituido por la estridencia de la discoteca, el tocadiscos o el televisor, y el arroyo cristalino por el curso de agua infesta y maloliente como residuo de humanas excretas.

Esta síntesis introductiva sobre la destrucción del medio ambiente en general, y del de nuestra Provincia en particular, acciones que se suceden a velocidad vertiginosa y con intensidad creciente, no tiene otro objetivo que tratar de mentalizar a los valencianos de la necesidad de tomar una medida urgente, de verdadera emergencia, para salvar lo que aún resta de nuestro patrimonio natural. Y las leyes no permiten otra más rápida y cautelar que el incluir con toda la prisa que sea posible lo más notable de nuestros espacios naturales en el catálogo que prevén las «Normas subsidiarias y complementarias de la Provincia de Valencia», fundamentado en el artículo 25 de la Ley del Suelo.

Tales espacios naturales provinciales e interprovinciales que reúnan primordial importancia se elevan a unos 20 y afectarán a unos 100 términos municipales, si bien en muy distinto grado, pues podrán existir Parques Naturales que, aunque comprendan, por ejemplo, 10 ó 12 términos, la mayoría de su superficie está contenida en tres o cuatro, siendo afectados los Municipios de una manera parcial por el Parque.

Esta medida cautelar no tiene otro objetivo que los equipos responsables de la ordenación territorial estudien detenidamente cualquier acción de asentamiento urbanístico que se pretenda realizar en dichos espacios u otro tipo de uso que pueda perjudicar tales áreas. Es el catálogo, además, medida previa a los Planes Especiales, que tendrán que reglamentar los usos, etc., de estos presuntos espacios naturales; labor dilatada que, de no tomar tal medida previa, podría comprometer la incomparable Naturaleza de la Provincia, cuya conservación es asunto tan vital, yo diría que de vida o muerte para nosotros $y$, sobre todo, para nuestros hijos y generaciones futuras. 
Por encima de todo interés privado y de la especulación del suelo, está el uso social de tales áreas, indispensables para la salud física y espiritual del pueblo, precisamente de aquellos sectores de la sociedad más deprimidos y que, aprisionados en la urbe, tienen pocas posibilidades de disfrutar de una Naturaleza que va pasando a ser posesión casi exclusiva de los ricos.

Por ello, no debemos consentir que se multipliquen los ejem. plos como el de El Saler y de tantos otros incomparables espacios malogrados por nuestra geografía provincial, y poner todos los valencianos nuestros esfuerzos en pro de que los Parques Naturales de nuestra Provincia y otros espacios protegidos sean pronto una realidad. Empezamos, pues, con el trabajo al cual nos vamos a referir en todo los artículos que seguirán.

\section{LA DIPUTACION PROVINCIAL EN LA PROMOCION DE PARQUES NATURALES}

«Las Normas subsidiarias y complementarias de planeamiento de ámbito provincial de Valencia" incluyen en su anexo III el catálogo de monumentos, jardines, parques naturales y paisajes, relacionando ordenadamente los mismos. Dicen las normas que el catálogo incluye los monumentos ya recon idos por el Ministerio de Educación y Ciencia y aquellos otros que se estiman de indiscutible catalogación y consiguiente defensa y promoción. Esta relación está virgen en cuanto a Parques Naturales se refiere, puesto que como tal concepto no figura ningún lugar de la Provincia, ya que la Albufera de Valencia se cita como una singularidad paisajística, cuando, desde luego, aparte de esta cualidad innegable, la Albufera debe ser catalogada junto con una amplia zona de su entorno, que se deberá limitar dentro del concepto de Parque Natural.

De todos los razonamientos aducidos resulta lógico que la Diputación provincial se haya propuesto realizar estudios encaminados a incluir en el catálogo de las "Normas subsidiarias y complementarias de planeamiento" los espacios naturales protegibles de la Provincia bajo el concepto de "Parques Naturales», que son los espacios más interesantes desde el punto de vista socio-económico, turístico y cultural y, además, los que, según el artículo $5 .^{\circ}$ de la Ley de 2 de mayo de 1975 sobre Espacios Naturales Protegidos, 
pueden ser propuestos por las Diputaciones y Ayuntamientos, así como por otras entidades y particulares, siendo su declaración por Decreto. Así, pues, el concepto de estos Parques se establece con criterios análogos, tanto en la Ley antes aludida como en las «Normas subsidiarias». Estos espacios tendrán que ser cuidadosamente valorados, delimitados y ordenados debidamente para su explotatación y uso, lo cual se hará mediante el Plan Especial correspondiente a que se refiere la Ley del Suelo y después incoarse expediente con arreglo a esta Ley o a la de Espacios Naturales Protegidos antes referida. Esta última no prevé medidas cautelares previas a la declaración de un espacio como protegido dentro de la clasificación que la misma contempla.

Otras vías para promover espacios naturales protegidos son los Planes Directores Territoriales de Coordinación y los Planes Generales de Ordenación municipal y comarcal. Los órganos públicos y privados competentes e interesados en la materia deben velar para que en estos Planes o en las "Normas subsidiarias de planeamiento" se cumplan las previsiones legales en orden a la prevención de los espacios naturales, calificándolos de suelo no urbanizable con arreglo al artículo $80, b$ ), de la Ley del Suelo actual.

La urgencia de la creación del catálogo provincial de espacios naturales protegibles, y en especial de Parques Naturales, ha surgido con motivo de algunas acciones graves de urbanización que afectaban a la Sierra Calderona, el lugar más interesante para el disfrute social y ordenado de la Naturaleza después de la parcial destrucción y privatización de la Dehesa y de El Saler.

Para la propuesta de los espacios naturales protegibles a incluir $\in n$ el catálogo, la Diputación ha constituido en principio una Comisión en la que, junto a políticos y técnicos de las Comisiones de Defensa de la Naturaleza y Ordenación Territorial, forman parte representaciones del ICONA provincial, Delegación de la Vivienda y Delegación de Información y Turismo.

Previamente, y como medida de urgencia, la Diputación propuso a la Comisión Provincial de Urbanismo y Vivienda la inclusión en el catálogo de las "Normas subsidiarias y complementarias de planeamiento" del Parque Natural de la Sierra Calderona por encima de la cota de los 300 metros, propuesta que deberá seguir los trámites determinados en la Ley del Suelo, uno de los cuales es el de información pública. Naturalmente que la propuesta sólo afecta a los enclaves de la Calderona en la Provincia de Valencia, pero en el 
futuro, para lograr una protección completa de esta importante Sierra, que es trascendente desde el punto de vista del esparcimiento, de su valor paisajístico, naturalístico, estético, forestal y de sus producciones, tendría que hacerse un Parque Natural interprovincial, llegando a un acuerdo de declaración, valoración y ordenación con la Provincia hermana de Castellón.

Esta propuesta de la Diputación y el correspondiente acuerdo de la Comisión Provincial de Urbanismo ha desencadenado una gran alarma en los Municipios incluidos en dicha Sierra, que, reunidos en Estivella, según noticias de la prensa, han manifestado su oposición a este proyecto y su deseo de oponerse al mismo en el período de información pública. Por si mis modestas opiniones pueden contribuir en algo a esclarecer el concepto de Parque Natural, el cual se maneja frecuentmente de modo totalmente equívoco por gentes no expertas en la protección de la Naturaleza y en las numerosas publicaciones de la prensa diaria, voy a desarrollar aqui lo que yo entiendo por el mismo, según lo dispuesto en las "Normas subsidiarias y complementarias de planeamiento de la Provincia».

\section{LA ZONIFICACION DEL PARQUE NATURAL Y LOS USOS PERMITIDOS}

En un Parque Natural se tendrá que realizar posteriormente a su catalogación una delimitación cuidadosa del mismo; una valoración, siguiendo los métodos técnicos apropiados, y, finalmente, una ordenación de sus usos y producciones. La delimitación del Parque comprenderá las siguientes zonas: 1. "La Reserva integral. 2." El Parque propiamente dicho. 3." El Periparque. En estas zonas los usos permitidos serán cada vez menos restringidos desde la primera zona a la tercera. Es absurdo creer, como hemos oído repetidas veces y casi a diario, que un Parque Natural es un lugar destinado únicamente al habitat de la fauna y flora, sin que quepan allí construcciones de ningún tipo, ni explotaciones agrícolas y ganaderas, ni los deportes, ni hoteles, etc. Bajo este craso error un Parque Natural significaría, en lugar de promocionar y aumentar la renta de los Municipios a los que pertenecen los terrenos donde está ubicado, la ruina de los mismos. Y es lamentable el que parezca haber gentes interesadas en sembrar este falaz concepto, que no son otras 
que personas cuyo interés en la especulación del suelo no tiene límites y quisieran urbanizar toda la Naturaleza con tal de conseguir con sus parcelaciones y chalés cuantiosas ganancias en detrimento del bien público al disminuir la calidad de la vida, especialmente de las gentes poco pudientes que, encerradas en las grandes urbes, no podrán tener así acceso a ese bien indispensable para su vida que es la Naturaleza, sobre todo a los pulmones verdes próximos a las zonas habitadas; :que son los que se privatizan primero por las construcciones de segunda residencia.

Es lástima que los pueblos se vayan despoblando por no saber aprovechar ese bien inigualable para el hombre de hoy que es el disfrute del medio natural. Que este medio no reciba los cuidados debidos por tal abandono y se vaya destruyendo por incendios, excursionismo incontrolado, vertidos y basuras, sin que puedan ordenarse y aprovecharse debidamente los recursos de la Naturaleza. Creo realmente absurdo que muchos Municipios no vean otra riqueza que tener su polígono industrial y su urbanización residencial correspondiente. Si éstas siguen proliferando de manera tan indiscriminada y anárquica, existen urbanizaciones y construcciones residenciales clandestinas en no poco número a lo largo y ancho del país, la ruina de nuestra Provincia y Región será un hecho no lejano e irreversible: Los espacios naturales urbanizados 0 industrializados ya no se recuperan más, y la calidad de la vida física y espiritual del hombre es tan baja que acarrea su miseria en medio de una absurda sociedad de consumo.

La zona de mayor uso y menores limitaciones del Parque Natural y que actúa de envuelta protectora del mismo es el Periparque. En éste pueden realizarse los aprovechamientos agrícolas, los forestales, los cinegéticos y los piscícolas. Los agrícolas quedan limitados a los existentes en el momento de la creación del Parque y, en cualquier caso, no deberán exceder de un 6 por 100 de la superficie del Periparque. Las demás explotaciones mencionadas deberán ser autorizadas con arreglo a los valores que se traten de proteger.

Por lo que respecta a las viviendas, se permitirán aquellas que constituyan pequeños núcleos urbanos de carácter rústico de acuerdo con el artículo 69 de la Ley del Suelo no reformada, artículo 85 de la actual.

Se permitirán núcleos de servicios, donde se podrán construir e integrar restaurantes, merenderos públicos, servicios sanitarios, cocinas de campo, zonas de aparcamiento, estaciones de servicio, 
hoteles, campings, instalaciones para la práctica de deportes y comercios. A estos núcleos se llegará por vía de comunicación apta para el paso de vehículos a motor.

Sin embargo, se prohibirán en el Periparque el uso de aparatos susceptibles de producir música o ruido cuando éstos se utilicen al aire libre y el bañarse en los lugares no autorizados.

En el Parque Natural propiamente dicho, los usos tendrán una restricción mayor, pero éstos son aún numerosos y tendentes al disfrute de la Naturaleza, al esparcimiento y a los servicios destinados a la comodidad de los visitantes, pero siempre que no perjudiquen a la conservación del Parque. La explotación ordenada de éste en tal zona será objeto de una importante fuente de riqueza para los pueblos y propietarios de los terrenos afectados. En este lugar, o Parque propiamente dicho, se podrán construir núcleos a donde se llegue por vehículos a motor y en los que podrán integrarse restaurantes, merenderos públicos, servicios sanitarios, cocinas de campo, zonas de aparcamiento, estaciones de servicio y venta fija de productos propios de un Parque, que se permitirá previa autorización.

Existirían, pues, zonas de picnic donde la gente pueda cocinar y comer sentados en mesas y bancos rústicos y en plena Naturaleza, tipo de los que ha instalado ICONA en Portacoeli.

Los aprovechamientos agricolas estarán permitidos, pero se limitarán a los existentes en el momento de la creación del Parque.

Se prohibirá el pernoctar, el uso de aparatos que produzcan música o ruido, navegación a motor, bañarse fuera de los sitios autorizados, dañar las plantas, molestar a los animales, alterar el suelo, colocar otros anuncios o carteles que no sean los propios del Parque y circular en vehículos si no es en vías autorizadas. Se prohibirán los aprovechamientos forestales, excepto en los casos en que se realice con fines de mejora del Parque por entresaca y previa autorización para cada fin.

También los aprovechamientos de pastos se limitarán a los existentes.

La caza estará prohibida, excepto cuando se realice por motivos científicos y con autorización.

La pesca podrá realizarse siempre que sea de modalidad deportiva.

No podrá haber explotaciones industriales, como las referentes a la minería, canteras, gravas, etc. 
Las explotaciones hidroeléctricas están prohibidas, aunque podrán tolerarse las existentes en el momento de su creación previa las obras de acondicionamiento paisajístico que sean necesarias.

En esta zona del Parque Natural, propiamente dicho, no podrán ubicarse hoteles ni campings, así como tampoco realizar construcciones para la práctica de deportes ni instalaciones eléctricas no enterradas.

\section{LA ORDENACION DE LA SIERRA CALDERONA: LA COTA TRESCIENTOS}

Cualquier forma de expropiación singular de la propiedad privada o derechos o intereses patrimoniales legítimos será objeto de indemnización, de acuerdo con lo establecido por la vigente legislación de expropiación forzosa.

La ordenación de un Parque Natural que figure en el catálogo de la Ley del Suelo será objeto de un Plan Especial, y, por tanto, los intereses afectados y perjudicados por el establecimiento del Parque se sujetarán a las compensaciones que se dispone para estos casos en los artículos correspondientes de la vigente Ley del Suelo.

También se fijarán por el Patronato del Parque las indemnizaciones que puedan producirse a las explotaciones agrícolas por animales salvajes como los jabalíes. Cualquier otra especie, perjudicial, por su excesiva multiplicación, a los intereses del Parque, podrá ser reducida en su expansión por los procedimientos que se determinen de acuerdo con las disposiciones vigentes del Ministerio de Agricultura.

También es un concepto erróneo el de aquellos que creen que los Parques Naturales son equivalentes a reservas de caza y que en ellos se introducen determinadas especies para su multiplicación que pueden perjudicar a las explotaciones agrícolas o de pastos que en el Parque Natural puedan existir. Por lo general se protege únicamente a la fauna existente y propia del Parque Natural, así como su flora, y se podrá controlar la primera cuando, por cualquier desequilibrio numérico, como está ocurriendo con el jabalí, resulte perjudicial.

Unicamente dentro de las llamadas zonas de reserva integral, necesariamente reducidas en comparación con la extensión total 
del Parque e incluidas en lo posible en las zonas más interiores, la protección de la fauna, flora y paisaje será total abarcando todos los aspectos de la Naturaleza. Ls visitas estarán sometidas a control; las únicas instalaciones permitidas serán las de auxilio al visitante y las destinadas a fines científicos, siempre que sean elementales y de carácter rústico. Los aprovechamientos en la zona de reserva estarán totalmente prohibidos. Cuando se publique el Reglamento de la Ley de Espacios Naturales Protegidos y se conozcan las líneas generales de usos restrictivos en los Parques $\mathrm{Na}$ turales, podrán adecuarse las medidas contenidas en las actuales "Normas subsidiarias de planeamiento de la Provincia» a aquéllas, unificándose así ambas disposiciones, lo que supongo será muy conveniente.

$\mathrm{Y}$ ahora vamos a referirnos a la mal interpretada cota de los 300 metros en la Sierra Calderona, por encima de la cual se ha malentendido no podrán realizarse ningún tipo de explotaciones agrícolas, de pastos, de construcción, etc. ¿Quién ha interpretado falsamente toda esta parte como de reserva integral? Esta sería la única zona del Parque Natural donde no cabría nada de esto, según hemos dicho, pero esta zona será reducida y habrá que determinarla cuando se valore el Parque. En la mayoría de estos espacios. situados por encima de los 300 metros, cabrá la instalación de todo lo que hemos enunciado para el Parque propiamente dicho o para el Periparque, según resulte de la ordenación, y estos usos son mu. chos, precisamente todos los compatibles con la conservación de la Naturaleza y con su explotación racional, con el disfrute de miles de personas y no con el de unos pocos pudientes que se hacen los dueños de nuestro entorno natural mediante la privatización de su suelo, que debe tener un interés social fundamentalmente.

Además entiendo que la cota trescientos no puede tomarse en términos absolutos, sino como una orientación, pues por encima de esta cota las condiciones de la Naturaleza, por sus características físicas, pendientes, comunicaciones, etc., ha hecho que en la Sierra Calderona no se ubiquen por lo general urbanizaciones a tal altura ni sea conveniente situarlas, con el fin de proteger a la $\mathrm{Na}$ turaleza y el uso y disfrute especial de la misma y no el privado. Utilización que será para los Ayuntamientos mucho más rentable a la' larga que el producido por las urbanizaciones particulares, que en unos casos se reduce sólo al de las licencias de construcción. 
Indudablemente existen lugares de la Sierra Calderona donde algún que otro Municipio está por encima de los 300 metros, y sus terrenos agrícolas y urbanizaciones se hallan situadas naturalmente por arriba de ese nivel. En este caso veo claro que como resultado de la valoración, delimitación minuciosa y ordenación detalla. da del Parque Natural de la Sierra Calderona, dichos lugares quedarán fuera del Parque o se incluirán en el Periparque.

Es indudable que con las medidas descritas, e incluidos en el Plan Especial, existirán terrenos más que suficientes para el Parque y también a cotas más bajas para hacer las urbanizaciones a que los pueblos aspiran. Por otra parte, dentro del Periparque caben construcciones y explotaciones muy amplias, sólo con las restricciones lógicas a la conservación y utilización social del suelo, y aún dentro del Parque propiamente dicho tienen acogida una serie de usos sociales altamente rentables.

Los estudios realizados por el Consejo Económico-Social Sindical de la Comarca de Sagunto con . respecto a la Sierra Calderona, son de un alto interés en muchos aspectos sociales y económicos, pero tenemos que lamentar hayan carecido del equipo técnico necesario que basase la conservación del medio ambiente físico de la Sierra Calderona en un estudio ecológico de la metodología y la amplitud que se debe exigir en estos casos.

Ello no es óbice para que pueda realizarse ahora en etapas sucesivas y encauzar científicamente, y sin perjuicio para la Naturaleza, las aspiraciones de los pueblos de la citada Sierra, que deben ser atendidos y ayudados al máximo en la noble tarea de conservar su medio físico, cosa perfectamente compatible si se completa el estudio realizado con una planificación científica y ecológica de la Naturaleza.

\section{EL MONTE PUBLICO, LOS ENCLAVES PRIVADOS Y LAS URBANIZACIONES}

En la Sierra Calderona, las 6.833 hectáreas de monte público pertenecientes a los distintos Municipios y las 2.119 del Estado tienen una distribución singular, ya que en gran parte son pequeñas manchas diseminadas, y por si no fuera poco aún existen $2.243 \mathrm{hec}$ táreas de enclaves privados incrustados en el monte público. Aparte de que las 6.833 hectáreas representan un tanto por ciento de la 
superficie de la Sierra que no llega aún ni al 10 por. 100 recomendado para los espacios naturales protegidos, existe el concepto erróneo en las opiniones de los Municipios componentes de esta Sierra de que los montes públicos deben constituir el Parque Natural. También afirman que alrededor de ellos deben ubicarse los núcleos urbanos residenciales y urbanizaciones de temporada o de vivienda permanente, sobre todo en las zonas próximas a la zona industrial de la IV Planta Siderúrgica. Hacer esto equivaldría sencillamente a destruir el monte público en muy poco tiempo. Usando una metáfora, diríamos más gráficamente que estos pulmones verdes rodeados del aire enrarecido que representa la fuerte presión e influencia humana de los alrededores traería consigo la enfermedad y muerte de estos órganos vitales para los valencianos. No pueden estar estos oasis de la Naturaleza rodeados de los peligrosos microbios de la presión urbana, de la depredación humana de todo tipo a que por experiencia sabemos es sometida la Naturaleza en estos casos y que la práctica ha demostrado terminarán por sucumbir. El caso de El Saler, donde se quería compatibilizar la conservación del monte con la urbanización residencial, ha sido bien patente y gráfico para todos los valencianos, y no es preciso describir aquí otros ejemplos que por estar más lejanos son menos conocidos para el gran público, pero no así para los técnicos.

Lo que se hace preciso y necesario es que por encima de la cota de los 300 metros, hablando de un modo general como antes he explicado, los núcleos de monte público no queden aislados y rodeados de urbanizaciones, sino que se reúnan en un todo continuo. Para ello es preciso añadir a los mismos los terrenos no públicos que los separan, los cuales podrán ser adquiridos a sus propietarios, o bien que éstos puedan usarlos según las normas que correspondan al Periparque o al Parque propiamente dicho, lo que dependerá de su situación. En general, por debajo de la cota trescientos quedan terrenos libres más que suficientes para las urbanizaciones, siendo éstos los de situación más cómoda por su topografía y proximidad a los núcleos urbanos, los cuales resultan mucho más beneficiados de las urbanizaciones próximas a ellos que de aquellas situadas en zonas separadas y de cota alta.

Por otro lado, es del todo urgente y necesario permutar por terrenos periféricos los enclaves particulares en el monte público. Estos de ningún modo deben poder ser convertidos en urbanizaciones privadas, pues tales construcciones supondrían un gravísi- 
mo peligro para la destrucción de tales espacios, considerándolas como un cáncer que, extendiendo su poder destructivo, acaba desorganizando y destruyendo el bosque. De no permutarse estos enclaves, sus propietarios deberán hacer de ellos sólo el uso que la ordenación del Parque Natural permita en estos casos y en consonancia con su situación.

Solamente formando esta orla continua por encima de los 300 metros, que constituirán los montes catalogados unidos ininterrumpidamente por los terrenos intermedios que se incorporarían al Parque, podemos decir que este espacio natural de la Sierra Calderona sería una realidad y marcaria un hito importantísimo en la salud espiritual y física de los habitantes del Area Metropolitana, aumentando la calidad de vida del valenciano y protegiendo así a los económicamente débiles, siempre con mucho los más perjudicados en la privatización de los espacios naturales.

Una vez dedicadas estas líneas al primer Parque Natural, que por su proximidad a la metrópoli es el más conflictivo y que por razones de urgencia se ha iniciado su inclusión en el catálogo a que se refiere el artículo 25 de la Ley del Suelo, tantas veces aludido, vamos a relacionar aquí otras áreas naturales de gran interés de la Provincia que deberán ser protegidas del mismo modo, incluyéndolas, como primera medida, en el catálogo.

\section{ESPACIOS NATURALES PROVINCIALES E INTERPROVINCIALES A PROTEGER}

1..$^{\circ}$ Sierra Calderona. 2. ${ }^{\circ}$ Dehesa, Albufera y su entorno. 3. 0 Otras zonas húmedas (marjales, lagunas, etc.) de la Provincia. Se indica aquí la Marjal de les Valls, de Puzol, de Tabernes, Jaraco y Jeresa; Estany de Cullera, desembocadura del Júcar y Laguna de San Lorenzo. 4. ${ }^{\circ}$ Pantano del Generalísimo y Serranía de Chelva. 5. Embalses de la Provincia y su entorno. 6. Sierra de la Puebla de San Miguel y sabinares dispersos en la comarca. $70^{\circ}$ Pico de Caroche y su entorno. $8 .^{\circ}$ Nacimiento del río Fraile y su entorno. 9. Pico del Tejo y su entorno. 10. Sierras Martes y Dos Aguas. 11. Diversos enclaves de tejos dispersos por la Provincia, así como los de alcornocales y sabinares, que deben ser zonas de reserva integral por su gran interés científico. 12. Valles de la Murta y Sierra de las Agujas. 13. El Monduber y su entorno. 14. Muela de Cortes de Pallás y 
su entorno. 15. La Unde y su entorno (interprovincial con Albacete). 16. Espacio interprovincial al norte entre la Provincia de Valencia y Castellón que comprendería, por parte de Valencia, terrenos de la Pobleta y Andilla, con la Peña Parde, de 1.312 m., y en la Provincia de Castellón terrenos de Sacanet, Segorbe y Altura. También la parte de la Sierra Calderona perteneciente a la Provincia de Castellón.

Los espacios naturales interprovinciales al sur, entre las Provincias de Valencia y Alicante, más importantes a proteger serían los siguientes:

17. Sierras de la Safor (Azafor) y Negra, que comprendería en Valencia terrenos de Villalonga y Oliva principalmente, y en la de Alicante, tierras de pueblos de Lorcha, Vall de Gallinera, Forna, Adsubia y Pego. 18. Sierra de Albaida-Benicadell, que se extendería por la Provincia de Valencia desde Agullent hasta más allá de Salem, y por lo que toca a Alicante comprendería tierras de Muro de Alcoy, Gallanes, Beniarres y otros. 19. Otros espacios naturales interprovincales más al sur serían los de la Sierra de Mariola y Sierra Umbría, con terrenos del término de Bocairente y otros, por lo que respecta a Valencia, y los de Bañeres, Alcoy, Cocentaina, Agres y Alfafara, por lo que respecta a Alicante.

\section{Espacios naturales interesantes de la Provincia de Castellón de la Plana}

1. Peñagolosa y su entorno. 2..$^{\circ}$ Desierto de las Palmas y Agujas de Benicasim. 3. Sierra de Espadán. 4. La Laguna de Almenara y su entorno. 5. ${ }^{\circ}$ Sierra de Engarcerán. 6. Atalayas de Alcalá. 7. ${ }^{\circ}$ Sierra de Valdancha. 8..$^{\circ}$ Sierra de Turmell. 9. Sierra del Carrascal y su entorno. 10. Espacios naturales interprovinciales con Valencia antes indicados.

2. Espacios naturales interesantes de la Provincia de Alicante

1. ${ }^{\circ}$ Pico del Montgó y su Sierra en las proximidades de Jávea. 2. Sierra de Aitana. 3. ${ }^{\circ}$ Font Rocha de Alcoy, de extraordinario interés botánico y que se debe defender a toda costa de urbanizaciones y otras presiones que puedan deteriorar sus ecosistemas. $4 .^{\circ}$ 
Sierra de Cabezón. 5. Sierra de Bernia. 6. Sierra de Alfaro. 7. Sierra de Serrella. 8. Sierra de Aixort. 9. Sierra de Peñarroja. 10. Sierra de Argüeña. 11. Los espacios naturales interprovinciales con Valencia antes mencionados. 12. Sierra de Maigmo y Sierra del Cid. 13. Como zona húmeda de gran interés y muy amenazada tenemos el litoral del bajo Vinalopó, que comprende la Albufera de Elche y zonas próximas al golfo de Santa Pola.

Este catálogo no es exhaustivo, ni mucho menos, comprendiendo sólo aquellas zonas más importantes, estando siempre abierto a las sugerencias de organismos públicos, sociedades proteccionistas y particulares, a las que invito desde estas líneas a promover la posible inclusión en el pretendido catálogo de otros espacios naturales, siempre que sean descritos convenientemente para razonar los motivos de su protección.

Las Diputaciones de Valencia, Castellón y Alicante tienen ante sí una importante tarea en lo tocante a la defensa y promoción de espacios naturales protegidos, y la Mancomunidad de las mismas debe compartir esta tarea, buscando aunar esfuerzos y directrices, sobre todo en lo tocante a los espacios naturales interprovinciales que antes señalamos, pues hemos de tener en cuenta que las unidades naturales están muchas veces comprendidas en extensiones que superan con mucho las divisiones administrativas a escala provincial e incluso regional.

Terminamos diciendo que es preciso pasar con la máxima urgencia de la fase de concienciación exclusivamente, de ese hablar continuo de la conservación de la Naturaleza, a los hechos reales. Pueblos y comarcas tendrán que dejar de lado egoísmos y puntos de vista estrechos por otros más amplios en beneficio de la comunidad. No podemos hablar de espacios naturales con calor de defensa y en aras de una ordenación bien planificada, para que cuando llegue el momento de aportar a ellos parte de nuestras tierras, consideremos esos espacios como algo improductivo y nefasto, tratando con razonamientos falaces que se elijan los de otros términos municipales ajenos a los nuestros. Ello sería estar en propia contradicción con lo predicado en el plano teórico cuando se llega a la realidad práctica.

Cada cosa en su sitio y cada sitio para una cosa, nos guste o no, pues de lo contrario, en vez de una ordenación del espacio natural, tendremos como resultado la anarquía resultante del juego de intereses privados. 


\section{URGENCIA DE AYUDAS ECONOMICAS PARA}

\section{LA PROMOCION DE NUESTROS ESPACIOS NATURALES}

Pensemos que los espacios naturales son fuente de riqueza para las comarcas y bienes que serán cada día más codiciados. Por ello, si los destruimos pensando en unos beneficios inmediatos y efímeros habremos comprometido para siempre el futuro del país y de las generaciones venideras.

Para evitar esto, y lograr la promoción de tales áreas naturales, apuntamos las siguientes medidas inmediatas:

a) El fomento de la ayuda oficial para la creación de fundaciones y asociaciones que promuevan y gestionen la protección de espacios y bienes naturales. Estas ayudas deberán ser lo suficientemente importantes para que se hiciera sentir de esta manera una disminución del déficit existente de estas zonas naturales, aproximadamente de sólo el 0,15 por 100 de la superficie del territorio nacional en lugar del 10 al 14 por 100 , como debería ser idealmente.

b) La dotación económica necesaria para que Diputaciones, Ayuntamientos, Fundaciones, Sociedades y Organismos del Estado, como ICONA, puedan actuar en consecuencia con el déficit actual de espacios naturales, pensando en todo momento que una acción de conservación requiere como contrapartida pagar o compensar a las partes afectadas.

c) La gestión de los espacios naturales de todo tipo y las posibilidades de su utilización turístico-recreativa, ha de ser objeto de especial cuidado y estudio en cada caso para evitar incongruencias o contradicciones con los fines perseguidos con la protección, y

d) La Administración deberá ir, en la explotación de los recursos naturales de estos espacios, por delante de lo que va la iniciativa privada en la creación de riquezas inmobiliarias, como las urbanizaciones que los destruyen, ofreciendo a los pueblos correspondientes las compensaciones necesarias por las restricciones de uso de los terrenos afectados, de modo que la utilización popular de la Naturaleza iguale al menos los beneficios inmediatos que los pueblos habrían de obtener de otros usos destructivos o deteriorantes de los espacios naturales. 
Nos oponemos rotundamente a la política sin sentido que sería la de proteger espacios, estableciendo las restricciones de uso necesarias, sin compensar a los Municipios afectados por los mismos. A toda acción negativa al respecto ha de suceder otra positiva y creadora de beneficios de otro género que equilibre aquélla y sea compatible con la conservación.

En el aspecto de los espacios naturales protegibles tenemos que citar a la Diputación de Barcelona como modelo al respecto, habiéndose incluido en el Plan de Ordenación de la Provincia de Barcelona 14 Parques Naturales, algunos de los cuales están en avanzado estado de ejecución y otros en proyecto. De estos Parques algunos son interprovinciales, entre las Provincias de Barcelona y Gerona o entre las de Barcelona y Lérida.

La Diputación de Barcelona ha dedicado varios cientos de millones de pesetas, recientemente cerca de 700 , para adquirir terrenos de propiedad privada en estos proyectados Parques.

En estos últimos años se ha visto que aquellos Parques incluidos en el Plan de Ordenación de 1963 eran insuficientes para la protección de los espacios naturales de la Provincia, surgiendo así el proyecto de crear 12 Parques comarcales más, con lo que se lograría una conservación importante y completa del medio natural.

Por otro lado, la Institución Catalana D'Historia Natural, de tanta tradición y prestigio, ha publicado un libro interesantísimo desde el punto de vista de protección de la Naturaleza, se trata del titulado ¿Natura, ús o abús?, que es en realidad un Libro Blanco de la gestión de la Naturaleza en los Paisos Catalans. En él, a través de cerca de 600 páginas, se sientan las bases para la protección de la Naturaleza, se analizan los hechos ocurridos en los Paisos Catalans que han conducido a la destrucción y deterioro del medio ambiente, poniendo de manifiesto causas y efectos y sentando las reglas a seguir para no caer de nuevo en los errores cometidos y llegar a una verdadera defensa y correcta planificación del medio natural.

Creo que todo lo expuesto nos debe hacer reflexionar profundamente sobre la situación de nuestra Provincia y Región, que está en "mantillas» verdaderamente en todos estos aspectos, estando interesada la Diputación a través de CODENA y de la Comisión de Ordenación Territorial, colaborando con ICONA las Delegaciones de la Vivienda y Turismo, así como otros organismos interesados en poner con urgencia remedio a esta situación, siendo instrumento importante para ello la propuesta del catálogo de espacios natura- 
les protegidos, ahora en estudio, y los condicionantes del medio físico para las acciones de la planificación de la Provincia, estudio que ha sido promovido por la Diputación y al que nos referiremos en otros artículos.

La presión industrial, urbanística y de turismo que sufre la Provincia determina que esta protección de la Naturaleza sea de suma urgencia y no pueda ya demorarse ni un día más, pues unos años perdidos conducirían a un caos irremediable. Los espacios incluidos en el catálogo tendrán que ser delimitados, valorados y ordenados cuidadosamente, señalando los usos posibles dentro de ellos. Pero en tanto se hace todo esto, lo cual necesariamente tiene que ser umu labor larga, la inclusión de estos espacios en el catálogo de las "Normas subsidiarias de planeamiento de la Provincia de Valencia» significará una medida cautelar importante, pues se habrá encendido en ellos como un gran semáforo rojo que indicará a los responsables de la planificación y de la ordenación territorial la cautela con que habrán de proceder antes de autorizar cualquier uso que pueda perjudicar tan trascendentes y vitales enclaves de la Provincia. 